\title{
The Relationship between Skills Training and Retention of Graduate Interns in a South Africa Information, Communication and Technology Company
}

\author{
Carva Pop \\ Gordon Institute of Business Science \\ University of Pretoria, South Africa
}

\author{
Nicolene Barkhuizen \\ Department of Human Resource Management \\ University of Pretoria, South Africa
}

\begin{abstract}
Substantial costs are associated with attrition of key talent in South African organizations. As a result, organisations invest in graduate internship programmes to attract and retain high calibre graduate interns. The main objective of the research was to determine whether soft skills and technical skills training, as part of a graduate internship programme, contributed to the retention of graduate interns in a South African Information, Communication and Technology (ICT) company. An exploratory, ex post facto research design was followed. A soft skills, technical skills and retention survey were administered among a purposive selected sample of graduate interns $(N=79)$ and mentors ( $N=39)$ in a South African ICT company. Both groups of participants indicated that the soft skills presented in the training are important. Combined, the respondents identified verbal communication, self-motivation, teamwork and goal directedness as the most important soft skills for graduate employability. Results further showed that the technical skills training contributed to a large extent to the employability of the graduate intern. Technical skills training were also significantly related to the graduate intern's intention to quit the internship programme. In conclusion, the current graduate internship programme focuses on the majority of employability soft skills required for the acquisition and retention of a job. Practical training is therefore important for the application of knowledge and to enhance graduate employability.
\end{abstract}

\section{Introduction}

The retention of new graduates is a challenge to many South African companies. Turnover among newly qualified graduates is high due to their ability to pursue and find alternative employment and the undersupply of skilled employees in the market. Newly appointed employees find it easier to leave and are constantly looking out for better prospects and more rewarding jobs in reputable firms and prestigious settings. This is in particular the case in the South African Information and Communication Technology Sector. A South Africa study on ICT skills concluded that in 2006 alone there were 104 000 vacancies in this sector, translated into $46 \%$ of unfilled posts [1].

It is thus imperative that companies retain new ICT graduates if they are suitable, skilled and respond well to on-the-job training given the alarming demand levels in this sector [1]. However, the problem is exacerbated by the fact that firms are generally not able to use new graduates to fill their skills requirements because most graduates have the qualifications but not the practical skills and experience. Other factors why new graduates are not employable are that that the wrong types of graduates are being produced (the need is for technical graduates), graduates are not suited for specialist positions, suitably skilled staff are often poached by other companies and graduates are not of a high enough quality [2]. Graduate employers are thus faced with the challenge of providing support and promoting appropriate forms of work experience (authentic rather than contrived) for new graduates [3]. Programmes to assist graduates to thrive in the real-world context of the workplace, providing opportunities to maximize the assets they acquire through the university experience will optimise their successful transition into organisations.

The high rate of unemployed graduates in South Africa, led to the inclusion of a category for new entrants in the National Skills Development Strategy 2 (NSDS2), which was implemented by the Department of Labour (DoL) in 2005. This would explain why the Sector Education and Training Authorities (SETAs) have registered and promoted graduate internship programmes to support the objectives set in the NSDS2. In addition, the National Government has through the Accelerated and Shared Growth Initiative for South Africa (ASGISA) identified key enabling areas, one of which is education and skills development. Within this area, a deliberate motivation for ensuring the NSDS works more efficiently to support economic activity is realised together with the 
acknowledgement of a challenge to prepare young people for work more effectively.

Based on the above it is clear that the development and retention of graduates on any kind of graduate internship programme is an area worthy of investigation in order to determine the components required for effective implementation of internship programmes to support both National Government strategies and organisational goals. The graduate internship programme in the case chosen for this research project was inaugurated in 2005 by the researcher (Pop) in a South African Information, Communication and Technology company. The key aim of the programme was to appoint ICT graduates from the designated groups and retain them in the organisation. The programme has shown success with the appointment and retention of the new graduates. It is within this context that the study will investigate the impact that the graduate internship programme had on the propensity to stay among the graduates and what factors the graduates perceive as being central to the their retention in the organisation. Flowing from data analysis, the study would recommend the key factors in a successful and effective graduate programme.

\section{Skills Training}

The lack of soft skills, workplace readiness and experience were the key consideration of the graduate internship programme where the research was conducted as part of the strategy to retain the graduates. At the start of their careers many graduates will lack the soft skills such as time management, creative thinking and general communication skills, goal and priority setting as well as team work, key capabilities identified by the Australian Chamber of Commerce and Industry [4].

The lack of soft skills is the main reason many graduates are unsuccessful in the recruitment phase. Relevant to the case study is the concern raised by the DPRU study [2] that many students come from historically Black institutions, where they do not have the opportunities to develop these skills by participating in co-operative education initiatives or extra-curricular activities allied to character building. Another study found that in many cases it was considered that skills and attributes had been developed outside the course of study which had proved more marketable in the graduate labour market than the type of degree acquired [5].

In support of the above, Hillage and Pollard [6] maintain that the 'employability assets' of an individual, and therefore a graduate as well, comprise knowledge (what they know), skills (what they do with what they know) and attitudes (how they do it). The study by the Scottish Higher Education Funding Council [3] provided a framework upon which to map the lists of assets, which new graduates should possess, as generated by Hillage and Pollard [6]:

- Traditional academic skills including specialist knowledge, ability to apply knowledge, logical thinking, critical analysis, problem-solving, written communication, spoken communication, ability to use numerical data, computer literacy and research skills;

- Personal development skills including selfconfidence, self discipline, self reliance, awareness of strengths and weaknesses, creativity, independence, knowledge of international affairs, desire to go on learning. To these could be added other essential personal attributes such as ability to reflect, reliability, integrity, honesty and regard for others; and

- Enterprise or business skills including entrepreneurial skills, ability to prioritise tasks, time management, interpersonal skills, presentation skills, ability to work in teams and leadership skills. To these could be added commercial awareness, flexibility, innovation, independence and risk taking [3]

\subsection{Soft Skills}

During the present turbulent economic times, the basic soft skills of communication, team work, delegating, appraising, presenting and motivating are now key to making businesses more profitable and better places to work. This reality is one of the reasons why companies are not just assessing their current staff and future recruits on their business/hard/technical skills but also on their soft skills [7]

Effective soft skills include the ability of people to balance the commercial needs of their company with the individual needs of their staff, while flexibility and ability to adapt to the changing needs of an organisation is a key soft skill, as is the ability to collaborate with others and influence situations through lateral and more creative thinking [8]. In addition, Menochelli [9] identifies examples of interpersonal/soft skills, such as friendliness, motivation, kindness, team spirit, negotiation instead of confrontation, team cohesiveness, understanding of different cultural and historical differences, motivation, team spirit, observance of rules, procedures and company etiquette, meaningful interpersonal skills, showing interest, solving skills, politeness, concise language, solid relations with diverse personality types, sociability, good interpersonal communication skills and similar traits.

Very few, if any, companies, especially in South Africa are untouched by the ever-widening influence of other cultures and good soft skills facilitate better communication and people's ability to manage differences effectively. It is in this context that the 
reality that soft skills can be developed and honed on an on-going basis through good training, insightful reading, and observation practice needs to be seen in the business cycle [10].

Pearce [11], one of the most astute business analysts of existing present and future skills trends and supply and demand analysis wrote as late as 2007 in his collection of articles on personnel patterns that:

\begin{abstract}
"There is a growing recognition that interpersonal skills are not simply helpful in business today; they are essential in today's highly focused, downsized and streamlined organizations where people tend to work in a series of small, often temporary workgroups or teams organized to accomplish short-term objectives." [11]
\end{abstract}

From the above it can be deduced that soft skills development is critical to the integration of graduates into the work place.

\subsection{Skills Deficiencies and Workplace Readiness}

Another factor to consider is the graduate's inability to work independently due to a lack of workplace exposure and experience. In South Africa the Universities of Technology have instituted the "Work-Integrated Learning" (WIL) model of training, where students spend some time at the workplace. According to the DPRU study [2], university graduates generally do not have any chance to gain working knowledge in their fields, and even though colleges often require students to complete an internship before graduating, these are hard to come by. The problem is exacerbated by the fact that many companies do not want to make an investment in training, or fear that other firms will simply poach staff once they have trained them. The Scottish Higher Education Funding Council [3] also found that work experience is a key determinant of graduates finding suitable employment.

The Scottish study concludes that the most frequently cited reason for obtaining their job by graduates surveyed who were 'very satisfied' with their career progress to date, was having had relevant work experience. The benefits of undertaking work experience while studying include developing a work ethic, developing personal skills, time management, relating to other people and workplace etiquette, communication (which in some disciplines were not considered to be taught as part of the degree) and applying learning and the ability to continue learning [3].
From a psychological standpoint, it is noted that the expectations of graduates are sometimes too high [2]. They expect that their qualifications will open the door to high salaries and management positions and are not willing to learn the skills that form the basis of employment and often feel that they do not need to start 'at the bottom' by virtue of being highly qualified in comparison with existing and older workers who do not have equal qualifications. More importantly, new graduates expect to be treated fairly and on par with their more experienced peers, given the human rights ethos that permeates higher education institutions currently. This is evidenced in the Markinor South African Employee relationship survey [12] where the most important factor that influences commitment to an organisation is fairness at work.

Similar concerns raised in the above studies may be relevant in the experience within the South African work context where graduate internship programmes have been implemented. This could also apply to the expectations that interns may have at the company where this study was conducted.

\subsection{Employability and Employer Needs}

Employability has become a global theme in higher education. Kruss [13] in a South African study on employability and higher education concluded that 'although employers and recent graduates agree that the undergraduate experience is enormously beneficial in terms both of personal development and workplace effectiveness, they are generally of the view that a degree course does not prepare students for work.' These studies show that there is a serious mismatch between graduate aspirations and the reality of the labour market and that new graduates are insufficiently prepared for the world of work. It is therefore understandable that employers are dissatisfied with the skills and attributes of recently qualified graduates and concerns are raised about their lack of generic skills [3].

Private sector leaders, according to Kruss [13], espoused a direct link between higher education and the job market, expecting higher education to directly prepare graduates with skills to make them employable. Higher education institutions were criticized because they do not offer adequate soft skills - problem solving, communication, entrepreneurship, good citizenship, managerial skills, leadership skills - 'generic skills that one needs to learn across any walk of life [13]. Brown, Green and Lauder [14] succinctly phrase this dilemma:

The volatile nature of consumer markets, the challenge to assumptions about lifetime employment, and the pace of technological innovations with built-in occupational 
obsolescence that demand regular periods of retraining are central features of the labour market changes leading to a new emphasis on 'employability'. The new worker is required to be flexible and adaptable and able to learn rapidly.

Skills and talent development are thus central to successful internship programmes. Hay [15] found that skills and capacity building for talent proved to be the most significant factor that pertains to employee well-being and retention. If managers take an interest in the career development of their staff, it has a profound influence on the emotional well-being of employees in the work situation. This factor is most relevant to new graduates who enter a company as they not only are eager to learn new skills and advance their careers, but also need the mentoring approach and a patient guide to show them the ropes and initiate them into the specific workplace. New graduates are very ambitious and want to climb the corporate ladder as quickly as possible. The Markinor South African employee relations survey also pointed out that career development is a major driver of employer loyalty and retention [12]. If new graduates feel that there are advancement opportunities in the organisation, the propensity to remain is higher. Opportunities for advancement also have an effect on the well-being of employees.

In conclusion, clearly then talent retention, specifically amongst graduates, is a serious concern in South Africa and should become an aspect of contemporary debate in many companies [16]. The new power-base in the labour market is a group of employees referred to variously as 'knowledge workers' [17]. In view of the ICT sector as a scare skill, one may consider the ICT graduate as a 'knowledge worker'. The value created by these individuals' means that organisations need knowledge workers far more than knowledge workers need them [17]. The investigation of the impact of a graduate internship programme as a retention strategy would not only benefit the research setting in which this study will be conducted, but also companies who employs ICT graduates.

In the light of the preceding, the following hypotheses were formulated for the research:

H 1: $\quad$ There is a statistically significant relationship between soft skills training and graduate interns intention to quit the internship programme

H 2: $\quad$ There is a statistically significant relationship between technical skills training and graduate interns intention to quit the internship programme

H3: $\quad$ There is a statistically significant relationship between soft skills training and mentor's intention to employ graduate interns

H4: $\quad$ There is a statistically significant relationship between technical skills training and the mentor's intention to employ the graduate intern

\section{Research Design}

\subsection{Research approach}

An exploratory, ex post facto quantitative research approach was followed. Ex post facto research is aimed at the discovery of possible causes for behavior (Watson, 2001). This type of research design can aid in identifying those dimensions of the graduate internship programme that contributes to the graduate's turnover intentions and the mentor's intention to employ graduate interns. Data was collected by means of surveys.

\subsection{Research Method}

3.2.1. Research Participants. This research focused on an ICT company that has implemented a graduate internship programme for IT graduates. A purposive sample was taken from graduate interns $(\mathrm{N}=79)$ and Mentors ( $\mathrm{N}=39)$, who participated in the internship programme during 2007 and 2008. This represented a response rate of $61 \%$ for the graduate interns and $75 \%$ for the mentors respectively. In this research mentors were primarily male (72\%), 30 years and older (90\%), had more than 10 years of work experience (87\%) and some sort of a tertiary education (84\%). Graduate intern respondents were primarily male (52\%), aged between 20-24 years (50\%) and hold bachelor degrees (64\%).

3.2.2. Measuring Instruments. The variables measured in this research were soft skills, technical skills, intention to quit and intention to employ. Soft skills and technical skills served as independent variables whereas intention to quit and intention to employ were measured as dependent variables. A brief description of the measurements is presented below.

- Soft skills - A soft skills questionnaire was developed based on the content of the soft skills training in the graduate internship programme. The questionnaire consisted of 16 items and was similar in content for both the graduate interns and mentors. Each respondent (mentor and graduate intern) was asked to rank the importance of 16 listed skills on a scale from 1 to 4: 1 = Insignificant and $4=$ Very important. After completion of this questionnaire the respondent was asked to identify any other soft skills not addressed in the training. Finally the respondents were asked to rank the five most important graduate soft skills for employability.

- Technical skills - Both group of respondents were asked to indicate the extent to which the technical skills training contributed to the technical skills of the graduate interns with a single item on a five-point scale from 1 to 5 : 1 $=$ to no extent and 5 = to a large extent. 
- Intention to quit - Graduate interns were asked to indicate the extent to which they considered quitting the graduate internship programme with a single item on a four-point scale from 1 to 4 : 1 $=$ Never and $4=$ Always.

- Intention to employ - Mentors were asked to indicate the extent to which they consider employing the graduate intern on completion of the programme with 1 item on a scale from 1 to 5: 1 = to no extent and 5 = to a large extent.

3.2.3. Research Procedure. A proposal that explained the aim and possible value of this research was presented to the Group Executive Human Resources of the target organisation, with a formal request for approval to conduct this research. The questionnaires were distributed electronically by the researcher. Clear instructions were provided. The purpose of the study and the benefits for both the participants and the company was highlighted. To ensure confidentiality and enhance reliability, the study was conducted anonymously.

3.2.4. Data Analysis. The statistical analysis was carried out with the SPSS Program. The reliability and validity of the Soft skills questionnaire were determined by means of Cronbach alpha coefficients, as well as exploratory factor analysis. Descriptive statistics (i.e., means, standard deviations) were used to analyse the data. Pearson-product moment correlations were used to analyse the significant relationships between soft skill and technical skills training and intention to quit (graduate intern)/ intention to employ (mentor). A cut-off point of $\mathrm{p}<$ 0,30 was used for statistical significance.

\section{Results}

The results are reported in two tiers. Tier 1 presents the results of the research in a descriptive format. Tier 2 focuses on the testing of the hypotheses.

\section{Tier 1:}

Respondents were first asked to indicate the importance of the soft skills in which the graduate interns received training. The results are reported in Table 1.

From Table 1 it is evident that the respondents ranked all the soft skills as very important. On average soft skills such as self-motivation, attentiveness, personal awareness, teamwork and goal-directedness were perceived as the most important skills among graduate interns. The most important soft skills as indicated by the mentors included goal-directedness, professionalism, conflict management, self-motivation and attentiveness. Graduate interns highlighted the need for additional training in people management, networking skills, diversity management, time management and listening skills. In addition, mentors highlighted the need for training in presentation skills, analytical thinking and time management.

Table 1. The Importance of Soft Skills Training

\begin{tabular}{|l|c|c|c|c|}
\hline \multirow{2}{*}{ Skill } & \multicolumn{2}{c|}{$\begin{array}{c}\text { Graduate Interns } \\
\mathrm{N}=79\end{array}$} & \multicolumn{2}{c|}{$\begin{array}{c}\text { Mentors } \\
\mathrm{N}=39\end{array}$} \\
\hline & Mean & $S D$ & Mean & $S D$ \\
\hline Goal-directedness & 3.75 & .466 & 3.67 & .478 \\
\hline Verbal communication & 3.67 & .524 & 3.41 & .498 \\
\hline Business writing skills & 3.56 & .549 & 3.67 & .569 \\
\hline Business Etiquette & 3.67 & .499 & 3.41 & .498 \\
\hline Verbal Communication & 3.70 & .515 & 3.31 & .703 \\
\hline Team work & 3.77 & .479 & 3.59 & .569 \\
\hline Conflict Management & 3.61 & .541 & 2.92 & .502 \\
\hline Resilience & 3.51 & .638 & 3.31 & .598 \\
\hline Personal awareness & 3.77 & .422 & 3.56 & .598 \\
\hline Interpersonal skills & 3.72 & .451 & 3.44 & .522 \\
\hline Problem solving & 3.61 & .517 & 3.44 & .556 \\
\hline Self-management & 3.56 & .549 & 3.21 & .493 \\
\hline Self-motivation & 3.82 & .384 & 3.51 & .478 \\
\hline Creativity & 3.63 & .511 & 3.38 & .647 \\
\hline Championing others & 3.58 & .569 & 3.67 & .409 \\
\hline Attentiveness & 3.78 & .414 & 3.28 & .590 \\
\hline
\end{tabular}

Next, the participants were asked to rank the five most important soft skills. The findings for the graduate interns are reported in Table 2.

Table 2. Most Important Soft Skills: Graduate Interns

\begin{tabular}{|l|l|l|l|c|}
\hline Item & Skill & N & $\%$ & Rank \\
\hline SSTI6 & Team work & 30 & 63.83 & 1 \\
\hline SSTI2 & Verbal communication & 25 & 53.19 & 2 \\
\hline SSTI13 & Self-motivation & 22 & 46.81 & 3 \\
\hline SSTI1 & Goal-directedness & 19 & 40.43 & 4 \\
\hline SSTI16 & Attentiveness & 19 & 40.43 & 5 \\
\hline SSTI15 & Creativity & 15 & 31.91 & 6 \\
\hline SSTI11 & Problem-solving & 15 & 31.91 & 6 \\
\hline SSTI4 & Business Etiquette & 13 & 27.66 & 7 \\
\hline SSTI5 & Non-verbal Communication & 13 & 27.66 & 7 \\
\hline SSTI9 & Personal Awareness & 12 & 25.53 & 8 \\
\hline SSTI10 & Interpersonal Skills & 11 & 23.40 & 9 \\
\hline SSTI12 & Self-management & 11 & 23.40 & 9 \\
\hline SSTI3 & Business writing skills & 8 & 17.02 & 10 \\
\hline SSTI8 & Resilience & 7 & 14.89 & 11 \\
\hline SSTI7 & Conflict Management & 6 & 12.77 & 12 \\
\hline SSTI15 & Championing others & 4 & 8.51 & 13 \\
\hline
\end{tabular}

The five most important soft skills as identified by the mentors are reported in Table 3.

Combined, both groups of respondents ranked verbal communication, self-motivation, goaldirectedness and team work among the top five important soft skills. In addition, graduate interns ranked attentiveness as one of the five most important soft skills, whereas the mentors ranked business etiquette as the most important soft skill. 
Table 3. Most Important Soft Skills: Mentors

\begin{tabular}{|l|l|l|c|c|}
\hline Item & Skill & $\mathrm{N}$ & $\%$ & Rank \\
\hline SSTI2 & Verbal Communication & 18 & 69.23 & 1 \\
\hline SSTI13 & Self-Motivation & 13 & 50.00 & 2 \\
\hline SSTI4 & Business Etiquette & 12 & 46.15 & 3 \\
\hline SSTI6 & Team work & 11 & 42.31 & 4 \\
\hline SSTI1 & Goal-directedness & 10 & 38.46 & 5 \\
\hline SSTI8 & Resilience & 8 & 30.77 & 6 \\
\hline SSTI10 & Interpersonal Skills & 8 & 30.77 & 6 \\
\hline SSTI15 & Creativity & 7 & 26.92 & 7 \\
\hline SSTI3 & Business Writing skills & 6 & 23.08 & 8 \\
\hline SSTI9 & Personal Awareness & 5 & 19.23 & 9 \\
\hline SSTI11 & Problem solving & 5 & 19.23 & 9 \\
\hline SSTI16 & Attentiveness & 5 & 19.23 & 9 \\
\hline SSTI5 & Non-verbal Communication & 4 & 15.38 & 10 \\
\hline SSTI15 & Championing others & 3 & 11.54 & 11 \\
\hline SSTI12 & Self-Management & 2 & 7.69 & 12 \\
\hline SSTI7 & Conflict Management & 1 & 3.85 & 13 \\
\hline
\end{tabular}

Other descriptive results showed that the majority of graduate interns (82.3\%) and mentors (84.6\%) indicated that the technical skills training contributed to the technical skills of the graduate interns. Graduate interns (57\%) indicated that they never considered quitting the internship programme. Mentors (94.9\%) indicated that they considered employing the graduate intern on completion of the graduate programme.

\section{Tier 2: Testing of Hypotheses}

Prior to testing the hypotheses, a principle-axis factor analysis was performed on the soft skills questionnaire. Item scores were inter-correlated and these matrices were subjected to the Kaiser-MeyerOlkin and Bartlett's tests for suitability for factor analyses. A single factor structure was obtained for the soft skills questionnaire. The factor was labeled soft skills and obtained an acceptable and reliable Cronbach alpha of 0.88 .

Subsequent to the factor analysis discussed above, Pearson product moment correlations were performed to test the hypotheses in this research. Pearson product moment correlation is used to determine the strength and direction of the relationship between variables, in this case the components of a graduate internship programme and intention to quit/employ. The result of the correlation between soft skills training and graduate interns' intention to quit is reported in Table 4.

Table 4. Pearson correlation between Soft skills Training and Intention to Quit

\begin{tabular}{|l|l|c|c|}
\hline & & $\begin{array}{c}\text { Soft skills } \\
\text { training }\end{array}$ & $\begin{array}{c}\text { Intention } \\
\text { to Quit }\end{array}$ \\
\hline $\begin{array}{l}\text { Soft skills } \\
\text { training }\end{array}$ & $\begin{array}{l}\text { Pearson } \\
\text { Correlation }\end{array}$ & 1 & .033 \\
\hline
\end{tabular}

\begin{tabular}{|l|l|c|c|}
\hline & Sig. (2-tailed) & & .774 \\
\cline { 2 - 4 } & $\mathrm{N}$ & 79 & 79 \\
\hline \multirow{3}{*}{$\begin{array}{l}\text { Intention } \\
\text { to Quit }\end{array}$} & $\begin{array}{l}\text { Pearson } \\
\text { Correlation }\end{array}$ & .033 & 1 \\
\cline { 2 - 4 } & Sig. (2-tailed) & .774 & \\
\cline { 2 - 4 } & $\mathrm{N}$ & 79 & 79 \\
\hline
\end{tabular}

* Statistically significant: $p<0,01$

+ Practically significant correlation (medium effect): $r>0,30$

++ Practically significant correlation (large effect): $r>0,50$

Table 4 shows that there is no statistically significant relationship between soft skills training and interns intention to quit the graduate internship programme. Hypothesis 1 is thus rejected.

The results of the correlation between technical skills training and graduate intern's intention to quit is reported in Table 5.

Table 5. Pearson correlation between Technical skills training and Intention to Quit

\begin{tabular}{|l|l|c|c|}
\hline & & $\begin{array}{c}\text { Technical } \\
\text { skills } \\
\text { training }\end{array}$ & $\begin{array}{c}\text { Intention to } \\
\text { Quit }\end{array}$ \\
\hline \multirow{2}{*}{$\begin{array}{l}\text { Technical } \\
\text { skills training }\end{array}$} & $\begin{array}{l}\text { Pearson } \\
\text { Correlation }\end{array}$ & 1 & $.285^{*}$ \\
\cline { 2 - 4 } & Sig. (2-tailed) & & .011 \\
\cline { 2 - 4 } & $\mathrm{N}$ & 79 & 79 \\
\hline \multirow{2}{*}{$\begin{array}{l}\text { Intention } \\
\text { Quit }\end{array}$} & Pearson & $.285^{*}$ & 1 \\
& Correlation & .011 & \\
\cline { 2 - 4 } & Sig. (2-tailed) & 79 & 79 \\
\cline { 2 - 4 } & $\mathrm{N}$ & & \\
\hline
\end{tabular}

* Statistically significant: $p<0,01$

+ Practically significant correlation (medium effect): $r>0,30$

++ Practically significant correlation (large effect): $r>0,50$

Table 5 shows a statistically significant positive correlation (low effect) between technical skills training and interns' intention to quit the graduate internship programme. Hypothesis 2 is accepted.

The results of the correlation between soft skills training and the mentor's intention to employ the graduate intern are reported in Table 6.

Table 6. Pearson Correlation between Soft skills training and Mentor's Intention to Employ Graduate Intern

\begin{tabular}{|l|l|c|c|}
\hline \multirow{2}{*}{} & & $\begin{array}{c}\text { Soft skills } \\
\text { Training }\end{array}$ & $\begin{array}{c}\text { Intention to } \\
\text { Employ }\end{array}$ \\
\hline \multirow{3}{*}{$\begin{array}{l}\text { Soft skills } \\
\text { Training }\end{array}$} & $\begin{array}{l}\text { Correlation } \\
\text { Coefficient }\end{array}$ & 1.000 & .214 \\
\cline { 2 - 4 } & Sig. (2-tailed) & $\cdot$ & .095 \\
\cline { 2 - 4 } & $\mathrm{N}$ & 39 & 39 \\
\hline \multirow{2}{*}{$\begin{array}{l}\text { Intention } \\
\text { Employ }\end{array}$} & $\begin{array}{l}\text { Correlation } \\
\text { Coefficient }\end{array}$ & .214 & 1.000 \\
\cline { 2 - 4 } & Sig. (2-tailed) & .095 & $\cdot$ \\
\cline { 2 - 4 } & $\mathrm{N}$ & 39 & 39 \\
\hline
\end{tabular}

* Statistically significant: $p<0,01$ 
+ Practically significant correlation (medium effect): $r>0,30$

++ Practically significant correlation (large effect): $r>0,50$

Table 6 shows that there is no statistically significant relationship between the importance of soft skills training and mentors intention to employ graduate interns upon completion of the programme. Hypothesis 3 is rejected.

The results of the correlation between technical skills training and graduate intern's intention to quit is reported in Table 7 .

Table 7. Pearson correlation between Technical skills training and Mentor's Intention to Employ the

\begin{tabular}{|l|l|c|c|}
\hline \multirow{2}{*}{} & & $\begin{array}{c}\text { Gechnic } \\
\text { al Skills } \\
\text { Trainin } \\
\text { g }\end{array}$ & $\begin{array}{c}\text { Intention to } \\
\text { Employ }\end{array}$ \\
\hline $\begin{array}{l}\text { Technical } \\
\text { Skills } \\
\text { Training }\end{array}$ & $\begin{array}{l}\text { Pearson } \\
\text { Correlation }\end{array}$ & 1 & -.076 \\
\cline { 2 - 4 } & $\begin{array}{l}\text { Sig. (2- } \\
\text { tailed) }\end{array}$ & & .648 \\
\cline { 2 - 4 } & $\mathrm{N}$ & 39 & 39 \\
\hline $\begin{array}{l}\text { Intention } \\
\text { Employ }\end{array}$ & $\begin{array}{l}\text { Pearson } \\
\text { Correlation }\end{array}$ & -.076 & 1 \\
\cline { 2 - 5 } & $\begin{array}{l}\text { Sig. } \\
\text { tailed) }\end{array}$ & .648 & \\
\cline { 2 - 5 } & $\mathrm{N}$ & 39 & 39 \\
\hline
\end{tabular}

* Statistically significant: $p<0,01$

+ Practically significant correlation (medium effect): $r>0,30$

++ Practically significant correlation (large effect): $r>0,50$

Table 7 shows that there is no statistically significant relationship between technical skills training and mentors intention to employ graduate interns. Hypothesis 4 is rejected.

\section{Discussion}

The war for graduate talent necessitates the development of very specific skills required by the workplace in the 21st century. In reality, companies are not just assessing their current staff and future recruits on their business/hard/technical skills only, but also on their soft skills [7]. The main objective of the research was to determine whether soft skills and technical skills training, as part of a graduate internship programme, contributed to the retention of graduate interns in a South ICT company.

Both groups of participants indicated that the soft skills presented in the training are very important. Combined, the participants identified verbal communication, self-motivation, teamwork and goal directedness as the most important for graduate employability. The results are in line with previous research [i.e. 3, 9, 13]. Yorke and Knight [cited in 19] indicated that employability is amongst others influenced by skilful practices (communication, time management, self and resources, problem-solving and lifelong learning) and meta-cognition (selfawareness and the capability to reflect on, in and for action). The interns highlighted the need for additional training in soft skills such as people management, networking skills, diversity management, time management and listening skills. The mentors on the other had included the need for additional soft skills such as analytical thinking, presentation skills and also time management. The Australian Chamber of Commerce and Industry [4] further indicated that many graduates will lack soft skills such as time management, creative thinking and general communication skills, goal and priority setting as well as team work. Although no statistically significant relationship was found between soft skills training and the intern's intention to quit the programme, the above results highlighted the importance of the soft skills training in the graduate internship programme. One can thus conclude that the graduate internship programme contributed to the most important soft skills identified for employability.

Results showed that the technical skills training contributed to a large extent to the graduate interns " employability. According to Smith and Kruger (cited in [20]) graduates are entering a more flexible, insecure and technology-dependent workplace than ever before and therefore need very specific skills required by the workplace in the 21st century. Recent research has identified the academic and technical skills as the most important category of skills required of graduates in the world of work [20]. These findings thus highlight the importance of practical training because learners do not always know how to apply their knowledge.

Technical skills training were statistically significant positively related to the interns " intention to quit the internship programme. In line with Hay [15], the findings results are ascribed to the fact that the graduate interns highlighted the need for more job specific training. In addition, mentors also indicated the need for more job specific training and maintained that training should occur earlier in the internship programme. This requires a more rigorous conceptualisation and planning of the graduate internship programme to ensure that the outcomes are achieved.

This research presented some limitations. A purposive sample was used in this research which means the findings cannot be generalised to other organisations. The research however identified and confirmed important soft skills that may be of relevance to other organisations for the employability and retention of graduate interns. The electronic nature of the research questionnaire posed a limitation to those participants in the population group that did not have access to the organisation' $\mathrm{s}$ network system due to being placed on a client site whose network limited connection to the employer 
information system network. This may be a possible explanation for the low response rate of mentors.

The present research took the format of a posttest only. This limited the researcher in terms of determining the contribution of the soft skills training, technical training and mentorship from an intern and mentor' s point of view. Action research should be undertaken with intervention training where measurements can be made on a consistent basis to determine whether the internship programme contributes to the soft skills of the graduate intern progressively. The methodology to measure soft skills should also be expanded to include observations.

This research only focused on the relationship between the components of a graduate internship programme and the retention of graduate interns. It is recommended that future research also focus on other factors such as organisational climate, commitment, job satisfaction, work engagement, work wellness (i.e. burnout, stress) and the impact thereof on the retention of graduate interns.

\section{Conclusion}

The absence of any research in the South African environment with regards to graduate interns' and mentors' perception on the role and relationship of soft skills, technical skills in the implementation of a graduate internship programme, makes this research stand out as unique and exploratory in the domain. Talent retention is an important topic of debate in the ICT sector in South Africa, given the context of a skills shortage, the relative scarcity of specialist employees and the mismatch between the supply from higher education institutions and the demands of the ICT workplace. It is within this context that this study investigated the experiences of both interns and mentors in a graduate intern programme, concomitant with the propensity of graduates to remain in the company after the completion of the programme.

The importance of soft skills has been strongly fore grounded in this research. At the start of their careers, many graduates will lack the soft skills such as Business etiquette, Conflict Management, Problem-solving, Self-Management and Goaldirectedness. The consequence of this is that they will be unsuccessful in the recruitment phase. The value of mentorship and a graduate intern programme is crucial, given the fact that university training is not aligned with the needs of the corporate workplace. It is with optimism that research of this nature would motivate companies to invest in graduate interns as it is an investment in our future talent.

\section{References}

[1] Paterson, A., (2007), ICT Skills in South Africa, Proceedings of the Colloquium on Information and Communication Technology education and training and the production of graduates, Pretoria: Human Sciences Research Council.

[2] Development Policy Research Unit (DPRU), (2007), Graduate unemployment in the face of skills shortages: A labour market paradox, Cape Town: University of Cape Town.

[3] Scottish Higher Education Funding Council, (2003), Higher Education: Higher ambitions? Edinburgh: Scottish Council Foundation.

[4] Human Sciences Research Council, (2008).

[5] Purcell, K., Pitcher, J. and Simm, C. (1999) Working out? Graduates' early experience of the labour market. CSU.

[6] Hillage, J and Pollard, E., (1998), Employability: Developing a framework for policy analysis. Institute for Employment Studies for Department of Education Research and Employment Research Brief No 85, DfEE.

[7] Collective Resources, (2008), A study of change patterns in the sugar industry. Durban.

[8] Strawn, J and Martinson, K., (2000), Steady Work and Better Jobs: How to Help Low-Income Parents Sustain Employment and Advance in the Workforce, Manpower Development Research Corporation: Philadelphia.

[9] Menochelli, J. (2006) Collateral Learning and the Soft Skills, SBS E-talks.

[10] Activia International, (2008), The increased value of soft skills, Activia:New York.

[11] Pearce, K., (2007), Skills demand and supply: The 21st century challenge, eSights Trends Book: New York.

[12] Markinor, (2003), 'South African employee relationship survey’; www.markinor.co.za/ERR.doc. (3 April 2009).

[13] Kruss, G. (2004), 'Employment and employability: expectations of higher education responsiveness in South Africa', Journal of Education Policy, 19, pp. 673-689.

[14] Brown, P., Green, A. and Lauder, H., (2001), High skills. Globalisation, competitiveness and skill formation, London: Oxford University Press.

[15] Hay, M., (2002), 'Strategies for survival in the war of talent', Career Development International, 6, pp. 52-55.

[16] Birt, M., Wallis, T. and Winternitz, T., (2004), 'Talent retention in a changing workplace: An investigation into variables considered important to South African talent', South African Journal of Business Management, 35, pp. 25-31. 
[17] Stewart, T. A., (1997), 'Brain power', Fortune, 17, pp. 67-68.

[18] Watson, J., (2001), 'Research Designs'; http://www.ecourse.amberton.edu (22 April 2009).

[19] Griesel, H. and Parker, B., (HRSC), (2008), Grappling with youth employability in South Africa. Employment, growth and development initiative, Pretoria: HRSC Press.

[20] Raftopoulous, M., Coetzee, S., and Visser, D., (2009), 'Work-readiness skills in the fasset sector', South African Journal of Human Resource Management, 7, pp. 1-8. 